\title{
Fable or Fact?: Did Janet Really Come to Repudiate His Dissociation Theory?
}

\author{
Martin J. Dorahy, PhD \\ Onno van der Hart, PhD
}

\begin{abstract}
Commencing in the late 1880s Pierre Janet developed the most complete theory of dissociation of his time. It has been suggested that Janet later repudiated his belief in dissociation theory (e.g., Hacking, 1995). Recently this viewpoint has been cited to support skepticism in dissociative identity disorder and researchers and clinicians of dissociation may be faced with such suggestions to challenge their work. The veracity of whether Janet actually recanted, or even lost interest in his dissociation theory is investigated through an examination of his later writings. Although Janet expanded his theoretical interests well beyond phenomena accounted for by dissociation, there is no evidence to indicate he renounced or lost confidence in his dissociation theory. [Article copies available for a fee from The Haworth Document Delivery Service: 1-800- HAWORTH. E-mail address: <docdelivery@ haworthpress.com> Website: <http://www.HaworthPress.com> (c) 2006 by The Haworth Press, Inc. All rights reserved.]
\end{abstract}

Martin J. Dorahy is affiliated with the Trauma Resource Centre and the School of Psychology at The Queen's University of Belfast, Northern Ireland.

Onno van der Hart is affiliated with the Department of Clinical Psychology at Utrecht University, Utrecht, The Netherlands, and the Sinai Center for Mental Health, Amsterdam, The Netherlands.

Address correspondence to: Martin J. Dorahy, PhD, School of Psychology, David Keir Building, The Queen's University of Belfast, Belfast, BT9 5BP, Northern Ireland (E-mail: m.dorahy@qub.ac.uk).

Journal of Trauma \& Dissociation, Vol. 7(2) 2006

Available online at http://www.haworthpress.com/web/JTD

(C) 2006 by The Haworth Press, Inc. All rights reserved.

doi:10.1300/J229v07n02_03 
KEYWORDS. Pierre Janet, Ian Hacking, dissociation theory, history of dissociation, dissociative disorders

Gifted young scholars in the fledgling years of their careers often develop theories that, with the evolution of their thinking and older and wiser minds, they drift away from, develop beyond being recognizable as anything related to the early theory, or recant completely. Perhaps the most famous example of this in the psychological literature is Freud's supplanting of the Seduction theory for his Intrapsychic Conflict model of neurotic symptoms and illness. In the same way that Freud apostatized his faith in the explanatory power of "Seduction," it has been suggested that Janet renounced conviction in his dissociation theory later in his life. For example, in his insightful commentary on the rise of schizophrenia and fall of dissociation and multiple personality in the early 20th century, Hacking (1995) indicates that Janet's declining interest in dissociation by 1909 was consistent with a paradigm shift away from hysteria in French psychiatry. Hacking cites Janet's 1919/25 book Psychological Healing as evidence for not only his declining interest in dissociation, but for his complete dismissal of the concept. Hacking suggests that in Psychological Healing Janet reconceptualized double personality (a form of dissociative personality division which was extensively studied in the late 19th century by many clinicians, including Janet's brother, Jules) as "a special and rare case" of manic depressive illness (p. 133). In deducing that Janet recanted his dissociative theory of multiple personality, Hacking writes, "Janet concluded that multiple personality was a special case of bipolar disorder" (p. 134, italics in original). In his more recent book Mad travelers: Reflections on the reality of transient mental illness, Hacking (1998) again repeats his conviction that Janet recanted his dissociation theory and belief in multiple personality.

Perhaps through a lack of familiarity with Janet's later writings, others have more implicitly indicated that he lost interest in his dissociation theory. For example, in a rich and fascinating account of Janet's efforts to develop his dissociation theory to explain the phenomenon of posthypnotic suggestion, LeBlanc (2001) states in the text of his article that dissociation theory "established the conceptual foundation of much of [Janet's] lifework and, arguably, of his general psychology of the unconscious" (p. 65); a position we certainly agree with. However, in the footnote that accompanied this passage, LeBlanc suggests that "[u]ntil at least 1898, Janet continued to build upon the general theory of dissociation he advanced in the late 1880s." By discussing and develop- 
ing his dissociation theory well after 1898 (e.g., Janet, 1901, 1907/1920, $1909,1911)$, we argue that while Janet expanded his intellectual focus into other aspects of psychological life he never lost confidence or interest in dissociation in his academically prolific life.

Historically critics of dissociative disorders have not cited the work of Janet nor Hacking's view regarding his dismissal of dissociation when proffering arguments against conditions such as dissociative identity disorder (DID). However Hacking's (1995, 1998) belief in Janet's recantation of dissociative theory and multiple personality, drawn from interpretations of his later work, is now being used to undermine the existence of dissociation and dissociative disorders (e.g., Kaplan \& Manicavasagar, 2001; McNally, 2003). For example, when challenging the existence of dissociative identity disorder, Barry-Walsh (2005) cites Hacking as support for the view that Janet "completely resiled" his belief in dissociation and the dissociative disorders (p. 110). Consequently, the accuracy of whether Janet actually repudiated his belief in dissociation becomes crucial.

Van der Hart $(1996,2005)$ has provided thorough critiques of Hacking's 1995 and 1998 monologues. Yet, as recent comments by Barry-Walsh indicate, the belief that Janet recanted his dissociation theory persists, and in order to challenge their work, researchers and clinicians of dissociation may be confronted with such suggestions. In an effort to assess its veracity, we examine whether Janet recanted or even drifted away from his belief in dissociation theory. The extremely difficult and almost unachievable task facing scholars interested in the work of Janet, Hacking and ourselves alike, is wading through his enormous bibliography of more than 20,000 printed pages, which spanned over 55 very productive years. In order to provide some structure we have attempted to limit this study to an examination of Janet's major works, several of which have been published in English. Whilst limited, some quotations from Janet's original work have been used and attempts have been made to indicate the context in which they were written. We have attempted to represent Janet fairly in our selection of quotations, and have not, for instance, discovered and then excluded quotations that we recognize as refuting our viewpoint.

\section{JANET AND THE THEORY OF DISSOCIATION}

Being influenced by the rising interest in dissociation which marked the 1880s in France (e.g., Ribot, 1885; Richet, 1884) and England 
(e.g., Myers, 1887), Janet, as a 30-year-old philosopher, produced in his 1889 doctoral thesis (L'automatisme psychologique: Essai de psychologie expérimentale sur les formes inférieures de l'activité humaine) what was then the most important and comprehensive account of dissociation (James, 1894). Arguing that dissociation reflected an undue division in the personality (or consciousness), Janet's theory not only provided an account of hysteria (see Janet, 1907, 1930), but also so-called automatic behaviors (e.g., automatic writing) and post-hypnotic suggestion (see LeBlanc, 2001). With reference to hysteria, Janet went on to argue (Janet, 1907) that it was characterized by a failure to integrate systems of ideas (e.g., cognitions, emotions) and psychobiological functions (e.g., behavioral actions). Failed integration could derive from a constitutional vulnerability in the individual, but was more likely caused by physical illness, exhaustion, or, most often, the vehement emotions inherent in traumatic experiences (Janet, 1889, 1909, 1911). Psychobiological systems which failed to integrate with the larger personality became self-organized into a smaller and generally more rudimentary part of the personality, which as well as having its own sense of self, could exert influence over the individual's behavior (for a more detailed outline and discussion of Janet's dissociation theory, see Ellenberger, 1970; Putnam, 1989; Van der Hart, \& Friedman, 1989; Van der Hart \& Horst, 1989; Van der Kolk \& Van der Hart, 1989).

The dynamic relationship within this basic divided structure gave rise to the dissociative symptoms inherent in hysteria, such as amnesia or bodily intrusions (e.g., tics). For example, amnesia was related to a complete division of both parts of the personality, whilst one part of the personality encroaching on the other led to bodily and psychological intrusions. Dispositional or environmental factors responsible for on-going integration failure could lead to the development of further divisions of the personality, and hence what is now known as dissociative identity disorder (DID). In his theory, Janet was clear to distinguish dissociation (divisions in personality) and its resultant phenomena (i.e., dissociative symptoms) from alterations in consciousness (e.g., lapses of attention, retraction of the field of consciousness), which often accompany dissociative episodes (e.g., Janet, 1907). Over the last 40 years this distinction has become lost (Nijenhuis, Van der Hart, \& Steele, 2002; Steele, Dorahy, Van der Hart, \& Nijenhuis, in press; Van der Hart \& Dorahy, in press; Van der Hart, Nijenhuis, Steele, \& Brown, 2004).

Like many of his contemporaries, including the New England physician Morton Prince (Dorahy 2004; Hale, 1975), Janet had grander 
designs for the theoretical model he developed to account for the discrete behavioral and clinical phenomena initially examined. Like Prince, Janet continued to develop both his theoretical framework and ideas to account for a much larger range of psychological phenomena. Janet hoped to link the disciplines of philosophy and medicine to the study of psychological phenomena by providing a shared language and framework for examining what he called the psychology of conduct (Janet, 1930, 1938). As part of this endeavor he instigated that both the realm of consciousness (e.g., mental phenomena such as thoughts and beliefs) and behavior should be understood and expressed in terms of actions, so as to provide a common language for observable and unobservable phenomena. Rooted in adult and child psychology, psychopathology, ethnology, and animal psychology, Janet constructed a so-called hierarchy of action tendencies, consisting of increasingly more complex actions, which he roughly divided into lower, middle, and higher tendencies (Ellenberger, 1970; Janet, 1926, 1938). Hysteriathe dissociative disorders in a generic sense-was characterized by the patient's actions oscillating between the two subgroups of the middle tendencies, that is, between reflexive and reflective beliefs and their related actions (Janet, 1920). Thus Janet's study of the human condition moved well beyond his initial focus on hysteria and into "both normal and ailing man" (Janet, 1930), but he continued to incorporate dissociation into his evolving, grand theoretical formulation.

Janet also remained committed to the comparative study of different psychopathologies in order to elucidate similarities and differences. As Hacking points out, Janet (1925) compared disorders of failed integration (i.e., hysteria) with what the French alienists called folie circulaire and German psychiatry referred to as manic-depression. In the dense chapter in which Janet argues that psychological mechanisms (i.e., suggestion) underlie the effectiveness of aesthesiogenic agents such as metals and magnets to elicit personality alterations, he discusses many cases of DID which he (e.g., Léonie) and others (e.g., Despine's Estelle; Azam's Félida) had published. In exploring these cases under the general banner of hysteria, he denotes the differences between morbid or illness states (parts of the personality) and apparently normal or what he called complete somnambulistic states. Morbid or illness states were defined by physical (somatic) symptoms such as contractures, anesthesia and disturbance of actions, as well as psychological symptoms, such as hyperamnesia for trauma memories, amnesia for memories of the normal state and mental depression (i.e., the inactivation of higher mental functions and integrative capacities). In a state of apparent nor- 
malcy or complete somnambulism, Janet (1925) noted that higher order integrative functions reappear, physical and psychological symptoms reside, though the individual becomes amnesic for the traumatic memory (e.g., see his discussion of Iréne, p. 812ff). Successful treatment, as Janet discusses much earlier in the text and highlights with the case of Iréne later in the book, relies upon making the apparently normal (complete somnambulistic) part of the personality aware and accepting of the traumatic memory (i.e., integrating the traumatic memory).

Janet (1925) went on to describe the morbid state using the term depression, because it was characterized by a reduction in "psychological tension" (i.e., the capacity to use one's psychic energy), which included a lowered capacity for integrative mental functioning. Thus, in an apparently normal state the patient functioned at a higher level of psychological tension with greater integrative capacity. These more adaptive tendencies were part of Janet's principle of excitation, which was at work during states of apparent normalcy. He distinguished the apparently normal state from the "maniacal phase" (p. 842) of bipolar disorder, which was characterized by low psychological tension as well as agitation. Thus for Janet, excitation was very different from agitation.

Janet likened the alterations between what he called the depression and excitation states in hysteria, with the alterations of phases in bipolar disorder (i.e., depression; excitation-i.e., periods of stable mood; and agitation-i.e., mania, which Janet conceptualized as an agitated depression rather than excitation). This may explain Hacking's interpretation that Janet came to view multiple personality as a form of bipolar disorder. However, Janet (1925) notes that in hysteria the switches between states can generally be induced by the clinician, whilst in true bipolar alterations between phases are not so characterized and occur spontaneously. As he concludes when describing his attempts to artificially induce phase alterations in bipolar: "I could not exercise the slightest influence upon their appearance" (p. 844). A further differentiating feature, according to Janet (1925), between the two sets of psychological disturbance was that hysteria was characterized by significant disruptions in the individual's sense of self (i.e., consciousness and memory) and various negative and positive dissociative symptoms. Such characteristics were not attributed to bipolar disorder.

Janet remained interested in, and continued to study, pathological dissociation as demonstrated in his 1929 chapter entitled "The double personalities," where he examined the modification of memory in DID and amnesia between dissociative parts of the personality (see Van der Hart, 1996). Throughout his life Janet continued to espouse his 
dissociation theory. In 1930, after the paradigm shift away from dissociation in psychiatry was basically complete, Janet mused, "I am still under the illusion that my early works were not in vain and that they have left some definite ideas" (p. 127). To this end he watched with interest and praised others who were following his lead and developing ideas of dissociation beyond traditional hysterical disorders and symptoms. For example, in commenting in 1937 on one of his former collaborators' (i.e., Henri Claude) efforts to extend the study of dissociation into psychotic illnesses, Janet stated:

One should recognize, as M. Claude has shown, that today the notion of psychological dissociation appears in a new form and presents interesting developments. It is not anymore presented exclusively with regard to hysteria alone, it appears as a characteristic common to many other mental disorders. The form that psychological dissociation presents in hysteria needs to be compared with and distinguished from schizophrenia and many other forms of psychological asthenia. (published in Claude, 1937, p. 246; see Van der Hart, 2005, for a more extended discussion)

The confidence Janet maintained in his theory of failed integration and psychological synthesis (i.e., dissociation) is demonstrated a year before his death, in a discussion on double and multiple personality. He argued:

[t]hese divisions of the personality offer us a good example of dissociations which can be formed in the mind when the laboriously constructed syntheses are destroyed. The unity, the identity, and personal initiative are not primitive characteristics of psychological life. They are incomplete results acquired with difficulty after long work, and they remain very fragile. All constructions built by the work of thought belong to the same genre: Scientific ideas, beliefs, memories, languages can be dissociated in the same way, and the end [product] of illnesses of the mind is the dissociation of tendencies as one observes in the most profound insanities. (Janet, 1946, p. 160)

\section{CONCLUSION}

In exploring other aspects of psychological functioning, Janet's focus on dissociative disorders (i.e., hysteria), and his use of the term "dissociation," decreased in his later writing. However, we argue from 
the current brief analysis for a different interpretation of Janet's later work than that which suggests he recanted his dissociation theory and belief in DID. Janet continued to discuss his theory of dissociation throughout his later writings, and right up to his death. He also incorporated dissociation into his ambitious attempt to develop a unified theory of psychological functioning. Consequently, we believe Janet took to his grave a strong conviction in the dissociative theory he had been so prominent in developing early in his career, which included as a central piece the concept and legitimate psychiatric existence of the dissociative disorders, including DID.

\section{REFERENCES}

Barry-Walsh, J. (2005). Dissociative identity disorder (Letter). Australian and New Zealand Journal of Psychiatry, 39, 109-110.

Dorahy, M.J. (2004). A review of Morton Prince's (1906) 'Hysteria from the point of view of dissociated personality.' UKSSD Newsletter, Issue 4. Web URL: www.ukssd.org.

Ellenberger, H.F. (1970). The discovery of the unconscious. New York: Basic Books.

Hacking, I. (1995). Rewriting the soul: Multiple personality and the science of memory. Princeton, NJ: Princeton University Press.

Hacking, I. (1998). Mad travelers: Reflections on the reality of transient mental illness. Cambridge, MA: Harvard University Press.

James, W. (1894). Book review. Psychological Review, 1, 195-199.

Janet, P. (1889). L'automatisme psychologique: Essai de psychologie expérimentale sur les formes inférieures de l'activité humaine. Paris: Félix Alcan. Reprint: Paris: Société Pierre Janet, 1973.

Janet, P. (1901). The mental state of hystericals. New York: G.P. Putnam's Sons.

Janet, P. (1907). The major symptoms of hysteria. London/New York: Macmillan. Reprint of 1920 edition: New York: Hafner, 1965.

Janet, P. (1909). Les névroses. Paris: Flammarion.

Janet, P. (1911). L'état mental des hystériques, sec. ed. Paris: F. Alcan.

Janet, P. (1919). Les médications psychologiques. Paris: F. Alcan.

Janet, P. (1920). Introduction to the second edition. In P. Janet (1920), The major symptoms of hysteria (2nd. ed. with new matter). New York; Macmillan.

Janet, P. (1925). Psychological healing. New York: Macmillan.

Janet, P. (1926). Les stades de l'évolution psychologique. Paris: A. Chahine.

Janet, P. (1929). L'évolution psychologue de la personnalité. Paris: A. Chahine.

Janet, P. (1930). Autobiography of Pierre Janet. In C. Murchinson (Ed.), History of Psychology in Autobiography, Vol 1 (pp. 123-133). Worcester, MA: Clark University Press.

Janet, P. (1938). La psychologie de la conduite. In H. Wallon (Ed.), Encyclopédie Française, tome VIII, la vie mentale (pp. 8 08-11 à 8 08-16). 
Janet, P., with the collaboration of H. Piéron and C. Lalo (1946). Manuel du baccalauréat, seconde partie, Philosophie: Questions complémentaires, 7th ed. Paris: Librairie Vuibert.

Kaplan, R. \& Manicavasagar, V. (2001). Is there a false memory syndrome? A review of three cases. Comprehensive Psychiatry, 42, 342-348.

LeBlanc, A. (2001). The origins of the concept of dissociation: Paul Janet, his nephew Pierre, and the problem of post-hypnotic suggestion. Historical Studies in the Physical and Biological Sciences, 39, 57-69.

McNally, R.J. (2003). Remembering trauma. Cambridge, MA: Belknap Press.

Myers, F.W.H. (1887). Multiplex personality. Proceedings of the Society of Psychical Research, 4, 496-514.

Nijenhuis, E.R.S., Van der Hart, O. \& Steele, K. (2002). The emerging psychobiology of trauma-related dissociation and dissociative disorders. In H. D'haenen, J.A. den Boer \& P. Willner (Eds.), Biological Psychiatry (pp. 1079-1098). Chicester, New York: John Wiley \& Sons.

Putnam, F.W. (1989). Pierre Janet and modern views of dissociation. Journal of Traumatic Stress, 2, 413-429.

Ribot, T. (1885). Les maladies de la personnalité. Paris: F. Alcan.

Richet, C. (1884). L'homme et l'intelligence: Fragments de physiologie et de psychologie. Paris: F. Alcan.

Steele, K., Dorahy, M., Van der Hart, O., \& Nijenhuis, E.R.S. (in press). Dissociation versus alterations in consciousness: Related but different concepts. In P. Dell \& J. O'Neil (Eds.), Dissociation and the dissociative disorders: DSM-V and beyond. Chicago: International Society for the Study of Dissociation.

Van der Hart, O. (1996). Ian Hacking on Pierre Janet: Observations. Dissociation, 9 , 80-84.

Van der Hart, O. (2005). I. Hacking on Pierre Janet: Observations. With a 2005 postscript. Janetian Studies, 2; Web URL: http://pierre-janet.com/JSArticles/ovdh05A. doc.

Van der Hart, O., \& Dorahy, M. (in press). Dissociation: History of a concept. In P. Dell \& J. O'Neil (Eds.), Dissociation and the dissociative disorders: DSM-V and beyond. Chicago: International Society for the Study of Dissociation.

Van der Hart, O., \& Friedman, B. (1989). A reader's guide to Pierre Janet on dissociation: A neglected intellectual heritage. Dissociation, 2(1), 3-16.

Van der Hart, O., \& Horst, R. (1989). The dissociation theory of Pierre Janet. Journal of Traumatic Stress, 2, 397-412.

Van der Kolk, B.A., \& Van der Hart, O. (1989). Pierre Janet and the breakdown of adaptation in psychological trauma. American Journal of Psychiatry, 146, 1530-1540.

RECEIVED: 08/09/05

REVISED: $10 / 13 / 05$

ACCEPTED: $10 / 14 / 05$ 